\title{
Serotonin, via HTR2 Receptors, Excites Neurons in a Cortical-like Premotor Nucleus Necessary for Song Learning and Production
}

\author{
William E. Wood, ${ }^{1}$ Peter V. Lovell, ${ }^{2}$ Claudio V. Mello, ${ }^{2}$ and David J. Perkel ${ }^{1}$ \\ ${ }^{1}$ Graduate Program in Neurobiology and Behavior, Departments of Biology and Otolaryngology, University of Washington, Seattle, Washington 98195, and \\ ${ }^{2}$ Department of Behavioral Neuroscience, Oregon Health and Sciences University, Portland, Oregon 97239
}

\begin{abstract}
Serotonin (5-HT) is a neuromodulator that is important for neural development, learning and memory, mood, and perception. Dysfunction of the serotonin system is central to depression and other clinically important mood disorders and has been linked with learning deficits. In mammals, 5-HT release from the raphe nuclei in the brainstem can modulate the functional properties of cortical neurons, influencing sensory and motor processing. Birds also have serotonergic neurons in the dorsal raphe, suggesting that 5-HT plays similar roles in sensory and motor processing, perhaps modulating brain circuitry underlying birdsong. To investigate this possibility, we measured the effects of 5-HT on spontaneous firing of projection neurons in the premotor robust nucleus of the arcopallium in brain slices from male zebra finches. These neurons are thought be akin to cortical layer V pyramidal neurons. 5-HT dramatically and reversibly enhanced the endogenous firing of RA neurons. Using pharmacological agonists and antagonists in vitro, we determined this action is mediated via HTR2 receptors, which we verified are expressed by in situ hybridization. Finally, focal administration of the serotonin selective reuptake inhibitor fluvoxamine revealed that endogenous 5-HT is sufficient to mediate this effect in vivo. These findings reveal a modulatory action of serotonin on the physiology of the song system circuitry and suggest a novel role of serotonin in regulating song production and/or learning; further understanding of the role of 5-HT in this system may help illuminate the complex role of this neuromodulator in social interactions and motor plasticity in humans.
\end{abstract}

\section{Introduction}

The biogenic amine serotonin (5-HT) is involved in modulating an array of complex behaviors, including sleep, anxiety, and mood (Dubovsky and Thomas, 1995; Monti, 2010). Perhaps it is not surprising, then, that serotonin deficiencies have been closely linked to mental illnesses such as anorexia, obsessive-compulsive disorders, and clinical depression. A primary treatment for these disorders has been use of antidepressants like the serotonin reuptake inhibitors (SSRIs) (Olfson and Marcus, 2009), which are now the most prescribed class of drug in the United States, with use nearly doubling between 1996 and 2005 (Olfson and Marcus, 2009); understanding the myriad ways in which serotonin affects brain function is thus a crucial goal from both health care and basic neuroscience viewpoints.

5 -HT is important for learning and memory function. For example, 5-HT is involved in perhaps the most comprehensively understood form of learning, sensitization of the gill and siphon withdrawal reflexes in Aplysia (Glanzman et al., 1989). More recently, a growing body of work has established that the serotonergic system affects multiple types of telencephalic associative

\footnotetext{
Received May 6, 2011; revised July 6, 2011; accepted Aug. 5, 2011.

Author contributions: C.V.M. and D.J.P. designed research; W.E.W. and P.V.L. performed research.

Correspondence should be addressed to William E. Wood, Neurobiology and Behavior, Box 356515, University of

Washington, Seattle, WA 98195-6515. E-mail: willwood@uw.edu.

DOI:10.1523/JNEUROSCI.2281-11.2011

Copyright $\odot 2011$ the authors $\quad 0270-6474 / 11 / 3113808-08 \$ 15.00 / 0$
}

learning in rodents (including visual discrimination, conditioned avoidance, eye blink conditioning), with HTR2A receptors seeming to play a dominant role (Williams et al., 2002; Harvey, 2003). Although the neural substrate of these neuromodulatory effects of serotonin is broadly known (i.e., the hippocampus and prefrontal cortex), the complexity of these areas in terms of their heterogeneity, multisensory processing, and interconnectedness makes it difficult to identify the specific loci or mechanisms of serotonergic action, from synapse to circuit, that ultimately produce the observed changes in learning.

Song production and vocal learning in zebra finches may be a particularly fruitful system in this context, as it consists in a complex but easily quantifiable learned skill (song) that is subserved by a set of discrete telencephalic nuclei, the song control system (SCS) (Zeigler and Marler, 2004; Nottebohm, 2005). The SCS can be divided into two pathways - an anterior forebrain pathway necessary for learning but not for production of adult song, and a direct motor pathway (DMP) that is both necessary and sufficient for normal adult song production (Fig. 1). These pathways converge on the final telencephalic song nucleus, the robust nucleus of the arcopallium (RA), which projects directly to the hypoglossal nucleus (nXII) and to brainstem respiratory control nuclei. All models of song sensorimotor learning involve some lasting synaptic changes that occur in RA (Abarbanel et al., 2004; Fiete et al., 2007; Gibb et al., 2009; Mooney, 2009).

Here, using in vitro single-unit and whole-cell electrophysiology, we show that 5-HT exerts a strong excitatory action on pro- 


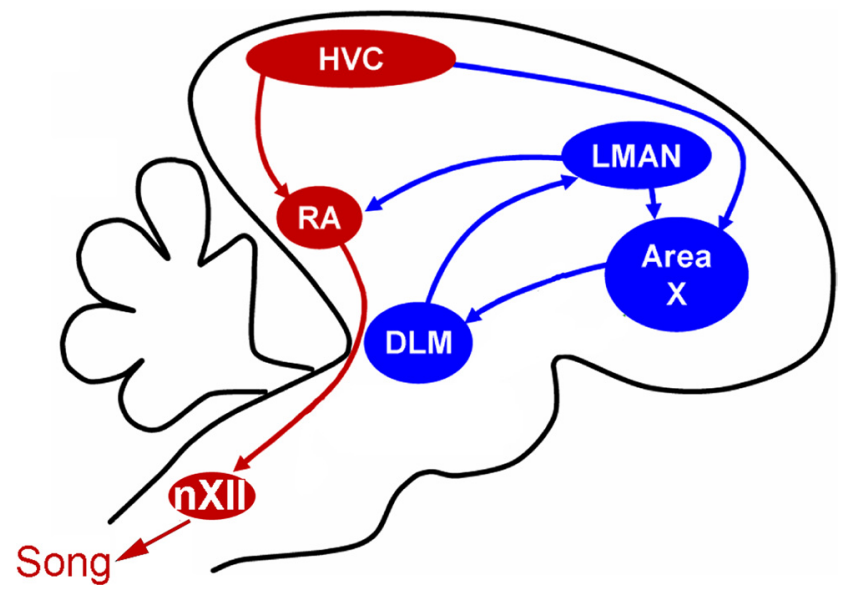

Figure 1. Simplified schematic view of the song control system. The direct motor pathway is in red, and the anterior forebrain pathway is in blue.

jection neurons of nucleus RA, which contains 5-HT (Barclay and Harding, 1988). Pharmacological manipulations and in situ hybridization point to HTR2 receptors mediating this action. While the exact channel mediating this action remains undetermined, we have ruled out the participation of $\mathrm{HCN}$ channels, L-type $\mathrm{Ca}^{2+}$ channels, and T-type $\mathrm{Ca}^{2+}$ channels. Blockade of 5-HT uptake revealed that endogenous 5-HT is sufficient to mediate this same increase in excitability. These findings establish serotonin as a potent modulator of the song control circuitry in the zebra finch.

\section{Materials and Methods}

Birds. Adult zebra finches (Taeniopygia guttata) were obtained from breeding colonies at the University of Washington or Oregon Health and Sciences University (OHSU), or purchased from an outside supplier. As only male zebra finches learn to sing and there is marked sexual dimorphism in the SCS, we restricted our study to males. Juvenile zebra finches in the sensorimotor period of song learning (days 38-54) were acquired from our breeding colony where they were housed with their family units until the experiment day. All birds were housed in groups of up to five individuals and experienced $12-13 \mathrm{~h}$ light per day. Food and water were provided ad libitum. All animal use protocols were approved by Institutional Animal Care and Use Committee committees at OHSU and University of Washington and are in accordance with NIH guidelines.

Preparation and application of drugs for electrophysiology experiments. All drugs were purchased from either Sigma-Aldrich [kynurenic acid (KA), picrotoxin (Ptx)] or Tocris [( \pm )-2,5-dimethoxy-4-iodoamphetamine hydrochloride (DOI), ketanserin, fluvoxamine]. All drugs for in vitro experiments were dissolved in water, with the exception of ketanserin, which was dissolved in DMSO. Final concentration of DMSO never exceeded $0.01 \%$, and controls were conclusive that this concentration had no effect on firing rate (FR) in these neurons. All drugs for in vivo experiments were dissolved in saline.

Preparation of brain slices for in vitro electrophysiological experiments. Methods for preparing slices have been described previously (Solis and Perkel, 2005). Briefly, each animal was anesthetized with isoflurane and killed by decapitation, and the brain was dissected rapidly into ice-cold, oxygenated artificial CSF (ACSF) containing the following (in mM): 119 $\mathrm{NaCl}, 2.5 \mathrm{KCl}, 1.3 \mathrm{MgSO}_{4}, 2.5 \mathrm{CaCl}_{2}, 1 \mathrm{NaH}_{2} \mathrm{PO}_{4}, 16.2 \mathrm{NaHCO}_{3}, 11$ D-glucose, and 10 HEPES, osmolarity adjusted to 310-320 mOsm with sucrose. Parasagittal or coronal brain slices (300 $\mu \mathrm{m}$ thick) were prepared using a Vibratome (Vibratome), and slices were stored at room temperature submerged in bubbled ACSF in which HEPES was replaced with equiosmolar $\mathrm{NaHCO}_{3}$.

In vitro electrophysiological slice recording. RA neurons fire rhythmically both in vivo and in vitro, although the firing rate in vitro (at $\left.30^{\circ}\right)$ is slightly less than one-half of in vivo rates $(4.784 \pm 2.1 \mathrm{~Hz}, n=97$, vs
$14.03 \pm 4.927, n=34$, in this study). Previous studies (Mooney, 1992; Park et al., 2005; Solis and Perkel, 2006; Sizemore and Perkel, 2008) have determined the overwhelming majority of spontaneously active cells in RA are projections neurons. Recording methods were similar to those described previously (Meitzen et al., 2007). We allowed the slices to rest for $1 \mathrm{~h}$ after collection before recording. For recording, a slice was submerged in a small chamber perfused with ACSF containing the fast glutamatergic and GABAergic transmission blockers kynurenic acid (1 mM) and picrotoxin $(150 \mu \mathrm{M})$ and maintained at $30^{\circ} \mathrm{C}\left( \pm 1^{\circ} \mathrm{C}\right)$. Single-unit extracellular recordings were obtained from neurons within a region that could be reliably identified as RA using transillumination. Only well isolated spikes with high signal-to-noise ratios were studied. Recording electrodes were made from pulled borosilicate glass pipettes (World Precision Instruments) with tips broken to a resistance of 4-10 $\mathrm{M} \Omega$ and filled with $0.9 \% \mathrm{NaCl}$. Extracellular potentials were amplified $1000 \times$ with an Axon MultiClamp 700B amplifier (Molecular Devices) and digitized with a Digidata 1322A (Molecular Devices) and stored on a personal computer using pClamp 9 (Molecular Devices).

In vivo electrophysiological recording. Methods were similar to those described previously (Gale and Perkel, 2010; Leblois et al., 2010). Birds were deprived of food and water for $1 \mathrm{~h}$ and then anesthetized by intramuscular injection of $20 \%$ urethane. Recording coordinates relative to the bifurcation of the midsagittal sinus were as follows (in $\mathrm{mm}$ ): anterior, -1:-0.5; lateral, 1.6:2.0; depth, 2.0:2.5. Small, iontophoretic injections of the tracer $10 \mathrm{kDa}$ dextran amine conjugated to Alexa 488 (Invitrogen) were made to mark recording locations, which were subsequently verified using standard histological methods previously described (Gale and Perkel, 2010).

Single-unit extracellular recordings were made using glass electrodes with tips broken to $0.5-3 \mu \mathrm{m}$ diameter. Electrodes were filled with $0.5 \mathrm{M}$ $\mathrm{NaCl}$. Voltage signals were amplified $10 \times$ with an Axoclamp 2B amplifier (Molecular Devices) in bridge mode, and then filtered $(0.1 \mathrm{kHz}$ high pass; $7 \mathrm{kHz}$ low pass) and amplified an additional $100 \times$ with a model 440 amplifier (Brownlee Precision). Signals were sampled at $25 \mathrm{kHz}$ with a Micro 1401 data acquisition unit and Spike2 software (Cambridge Electronic Design).

Electrophysiological data analysis. Spikes from both the in vitro and in vivo experiments were sorted using Spike2 (CED) software and analyzed using custom software written in MATLAB (MathWorks). Unit isolation was verified based on examination of overlaid spike waveforms and a plot of the principal components of the spike waveform calculated in Spike2 ,tk;4for consistency of spike shape, and evidence of a refractory period in a histogram of interspike intervals. Signal-to-noise of single units was generally $>3: 1$.

Tissue preparation for in situ hybridization. Six adult male zebra finches were isolated overnight under a $12 \mathrm{~h}$ light/dark cycle (same as breeding aviary) in custom-built acoustic isolation chambers. The following morning, birds were monitored for at least $2 \mathrm{~h}$ to ensure they were not singing and were then killed by decapitation. Their brains were quickly removed, blocked in the parasagittal plane, and frozen in Tissue-Tek OCT compound (Sakura Finetek) in a dry ice/isopropanol bath. Parasagittal $(10 \mu \mathrm{m})$ brain sections were cut on a cryostat, melted onto microscope slides (Superfrost Plus; Thermo Fisher Scientific), and stored at $-80^{\circ} \mathrm{C}$ for in situ hybridization.

In situ hybridization for serotonin receptor $2 A, 2 B$, and 2C (HTR2A/ HTR2B/HTR2C). Digoxygenin (DIG)-labeled riboprobes were synthesized using established protocols (Lovell and Mello, 2011). Briefly, clones corresponding to HTR2A (GenBank accession code CK306989), HTR2B (FE732340), and HTR2C (DV953355) were obtained from the ESTIMA zebra finch brain cDNA collection (http://titan.biotec.uiuc.edu/cgi-bin/ ESTWebsite/estima_start?seqSet=songbird3). Plasmid DNA was extracted (GeneJET Plasmid Miniprep kit; Fermentas), restriction enzyme digested (BSSHII; New England Biolabs) to release the insert template, and twice purified with a PCR purification kit (GeneJET PCR Purification Kit). Sense and antisense strand probes were then synthesized at $37^{\circ} \mathrm{C}$ for $5 \mathrm{~h}$ using the appropriate T3 or T7 RNA polymerase (Promega) and nucleotide label mix, and purified by Sephadex G-50 columns.

All of the methods for in situ hybridization were essentially as described by Lovell and Mello (2011). Brain sections were postfixed in a 3\% 


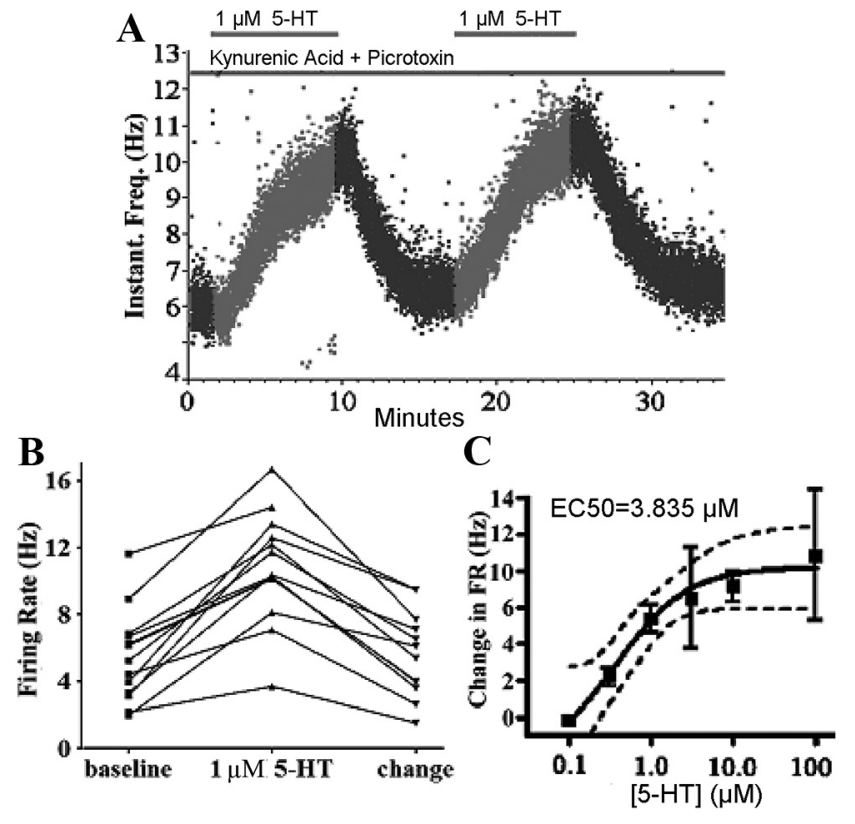

Figure 2. 5-HT causes an increase in the spontaneous firing rate of RA projection neurons. $A$, Plot of instantaneous firing rate versus time for one example neuron. $\boldsymbol{B}, 5$ - $\mathrm{HT}$ increased spontaneous activity in every RA projection neuron tested. $C$, A dose-response curve indicates that half-maximal effects occur with $\sim 3.8 \mu \mathrm{m} 5$-HT. All experiments were done in the presence of KA and Ptx. Error bars indicate SEM.

buffered paraformaldehyde solution for $5 \mathrm{~min}$ at room temperature (RT), rinsed twice in $0.1 \mathrm{M}$ PBS, and dehydrated through an alcohol series. Sections were acetylated for $10 \mathrm{~min}$ in a solution of $1.35 \%$ triethanolamine and $0.25 \%$ acetic anhydride in water, and rinsed three times with $2 \times$ SSPE containing the following (in $\mathrm{mm}$ ): $300 \mathrm{NaCl}, 20 \mathrm{NaH}_{2} \mathrm{PO}_{4}$ $\mathrm{H}_{2} \mathrm{O}$, and 2.5 EDTA, pH 7.4. Each section was then hybridized with a solution $(16 \mu \mathrm{l})$ containing $50 \%$ deionized formamide, $2 \times$ SSPE, 1 $\mu \mathrm{g} / \mu \mathrm{l}$ tRNA, $1 \mu \mathrm{g} / \mu \mathrm{l} \mathrm{BSA}, 1 \mu \mathrm{g} / \mu \mathrm{l}$ poly(A) in DEPC-treated water, and $1 \mu \mathrm{l}$ of DIG-labeled riboprobe. Slides were coverslipped, sealed by immersion in mineral oil, and incubated overnight at $65^{\circ} \mathrm{C}$. The following day, sections were rinsed in chloroform, de-coverslipped in $2 \times$ SSPE, and washed by incubating serially for $1 \mathrm{~h}$ at RT in $2 \times \mathrm{SSPE}, 1 \mathrm{~h}$ at $65^{\circ} \mathrm{C}$ in $2 \times$ SSPE containing $50 \%$ formamide, and twice in $0.1 \times$ SSPE for $30 \mathrm{~min}$ at $65^{\circ} \mathrm{C}$.

Sections were blocked for $30 \mathrm{~min}$ at RT in TNB buffer (100 mM Tris$\mathrm{HCl}, \mathrm{pH} 7.4,150 \mathrm{~mm} \mathrm{NaCl}, 20 \mu \mathrm{g} / \mu \mathrm{l}$ bovine serum albumin, $0.3 \%$ Triton $\mathrm{X}-100)$, and then washed three times in TNT (100 mM Tris-HCl, pH 7.4, $150 \mathrm{~mm} \mathrm{NaCl}, 0.3 \%$ Triton X-100). Sections were then incubated for $2 \mathrm{~h}$ in TNB with an alkaline phosphatase-conjugated anti-DIG antibody (antiDIG-AP; 1:300 dilution; Roche Applied Science), washed three times for $5 \mathrm{~min}$ in TNT, and incubated for $1-3 \mathrm{~d}$ in a ready-to-use Tris-buffered solution containing the alkaline phosphatase substrates nitroblue tetrazolium chloride (NBT) $(0.42 \mathrm{~g} / \mathrm{L})$ and BCIP (BCIP/NBT; $0.21 \mathrm{~g} / \mathrm{L}$; Substrate Solution NEL937; PerkinElmer). Slides were washed three times for $5 \mathrm{~min}$ at RT in TNT, rinsed briefly in distilled water to remove salts, and coverslipped with Vectamount AQ (Vector Laboratories).

\section{Results}

\section{5-HT increases the spontaneous firing rate of RA neurons in vitro}

To investigate a possible serotonergic modulation of the firing properties of RA projection neurons, we recorded intrinsic spontaneous activity using the relatively noninvasive (compared with whole-cell techniques) single-unit extracellular recording configuration. All cells recorded were RA projection neurons. Bath application of 5-HT $(1-100 \mu \mathrm{M})$ increased the intrinsic spontaneous firing rate of RA neurons (Fig. $2 A, B$ ), often by a
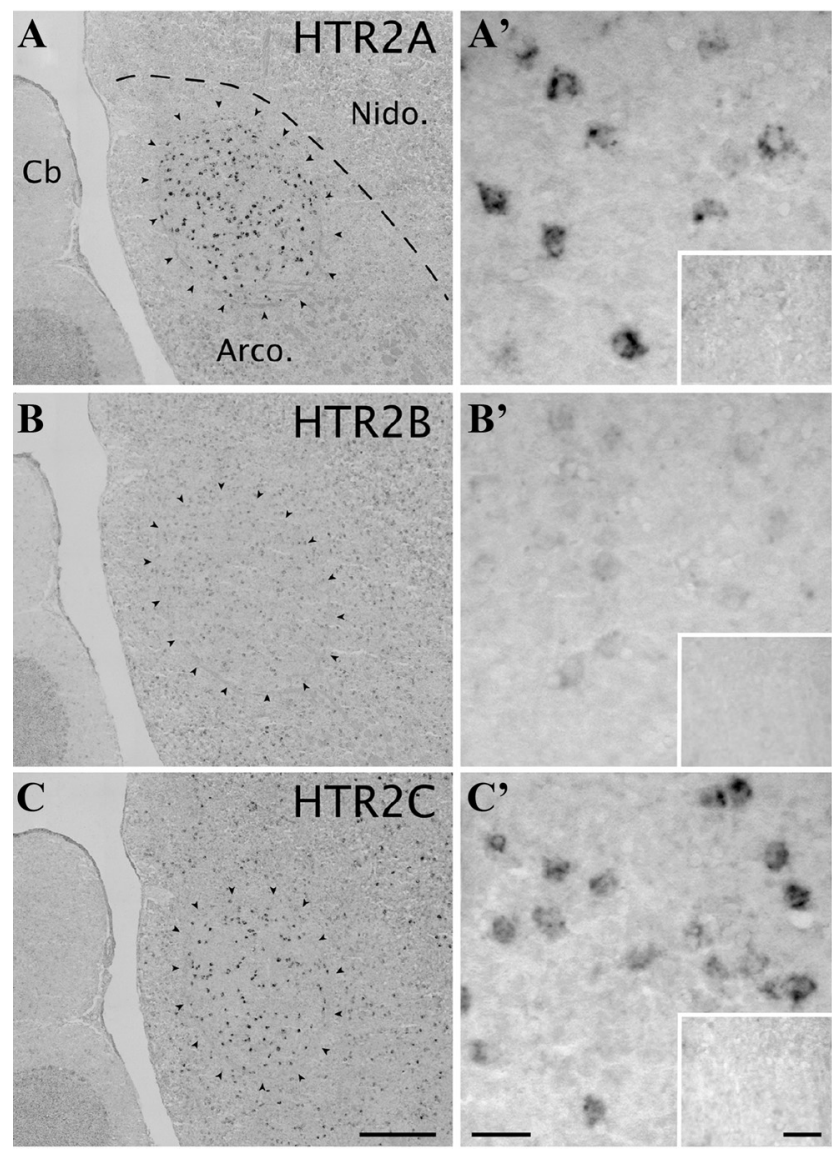

Figure 3. HTR2A, HTR2B, and HTR2C expression in the arcopallium of an adult male zebra finch. $\boldsymbol{A}-\boldsymbol{C}$, High-resolution photo-montaged images of $H \operatorname{TR2A}(\boldsymbol{A}), \operatorname{HTR2B}(\boldsymbol{B})$, and $H \operatorname{TR2} C(\boldsymbol{C})$ in situ hybridization data in parasagittal brain sections $\sim 1.8 \mathrm{~mm}$ from the midline. The location of the RA is indicated in each panel by arrowheads. $A^{\prime}-C^{\prime}$, High-magnification views of $H T R 2 A$ $\left(\boldsymbol{A}^{\prime}\right), \operatorname{HTR2B}\left(\boldsymbol{B}^{\prime}\right)$, and $H \operatorname{TR2}\left(\boldsymbol{C}^{\prime}\right)$ labeled cells in RA. Based on soma size, these likely correspond to RA projecting neurons. The inset panels show high-magnification views of sense strand hybridizations; no labeling was detected, supporting demonstrating probe specificity. Scale bars: $\boldsymbol{A}-\boldsymbol{C}, 250 \mu \mathrm{m} ; \boldsymbol{A}^{\prime}-\boldsymbol{C}^{\prime}, 25 \mu \mathrm{m}$. Anatomical abbreviations: Arco., Arcopallium; Nido., nidopallium; $\mathrm{Cb}$, cerebellum.

factor of $2(p<0.0001, \Delta \mathrm{FR}=5.4 \mathrm{~Hz}, n=13$, for $1 \mu \mathrm{M} 5-\mathrm{HT})$. This effect was reversible to baseline levels in 5-20 min upon washout of 5-HT. All units recorded during application of $1 \mu \mathrm{M}$ 5 -HT showed an increase in firing rate (Fig. $2 \mathrm{~B}$ ). All in vitro experiments were performed in the presence of the ionotropic glutamatergic and GABAergic transmission blockers, kynurenic acid and picrotoxin, respectively. We determined that the halfmaximal effect $\left(\mathrm{EC}_{50}\right)$ for 5-HT was $3.85 \mu \mathrm{M}$ (Fig. $2 \mathrm{~B}$ ), similar to that found in a previous study looking at depolarizing responses of HTR2 receptors in rodent layer V pyramidal neurons in association cortex (Araneda and Andrade, 1991). We therefore focused our experiments on this class of receptors.

\section{HTR2 receptor mRNAs are expressed in RA}

A comprehensive search of the zebra finch genome (taeGut3.2.4) revealed three distinct loci encoding the zebra finch orthologs of HTR2 serotonin receptors (HTR2A, HTR2B, and HTR2C). Here, we use the human gene nomenclature convention (Bruford et al., 2008) (uppercase italics for gene and mRNA; uppercase for protein). Based on a comparison of predicted amino acid residues within protein coding domains HTR2A showed 90, 74, and 76\% identity at the amino acid level with chicken, mouse, and human, 

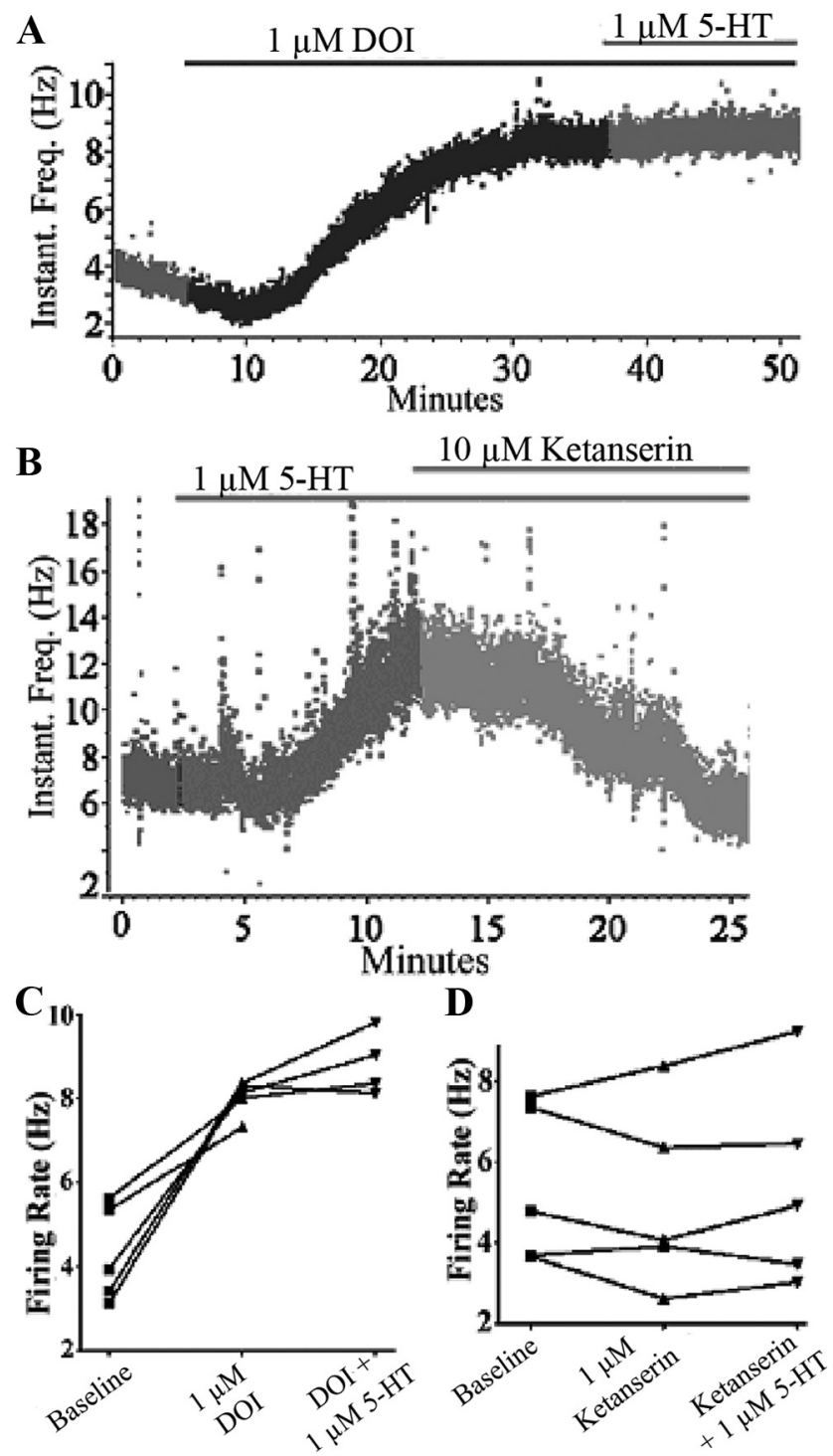

Figure 4. $5-\mathrm{HT}_{2}$ receptors mediate the increase in spontaneous firing rate. $\boldsymbol{A}$, The $5-\mathrm{HT}_{2 \mathrm{~A} / \mathrm{C}}$-specific agonist DOI both mimics and occludes the effect of $5-\mathrm{HT}$. B, The $5-\mathrm{HT}_{2 \mathrm{~A} /}$ c-specific antagonist ketanserin blocks the effect of 5 -HT. Ketanserin can be applied either before 5-HT (data not shown) or after (shown here). C, Group data of firing rate before and after DOI. D, Group data showing that ketanserin, when applied before 5-HT, blocks the increase in firing rate. All experiments were done in the presence of $\mathrm{KA}$ and Ptx.
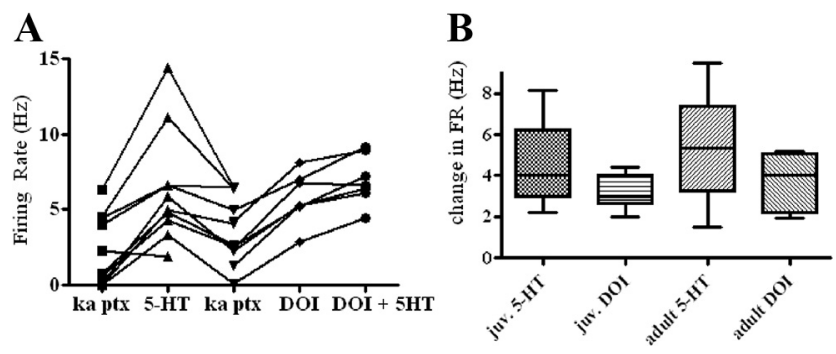

Figure 5. HTR2 receptors are present and active in juvenile zebra finches (day 38 - 54), just as in adults. A, 5-HT causes an increase in firing rate of RA projection neurons in juvenile zebra finches, which is mimicked and occluded by the HTR2-specific agonist, DOI. $\boldsymbol{B}$, The change in firing rate induced by $5-\mathrm{HT}$ and/or $\mathrm{DOl}$ is indistinguishable between juveniles and adults. All experiments were done in the presence of KA and Ptx.
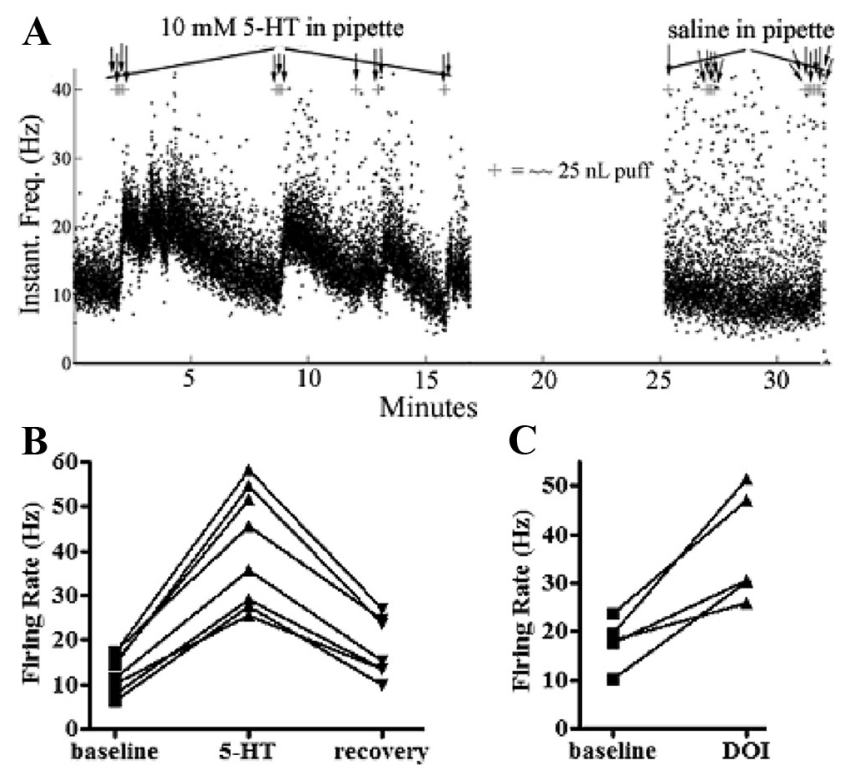

Figure 6. 5-HT, via HTR2 receptors, also causes an increase in spontaneous activity in vivo. $A$, Plot of instantaneous firing rate (IFR) versus time for one example neuron. IFR plot subsequent to the break indicates that, following several applications of 5-HT, the injection pipette was removed and replaced with one containing saline. $\boldsymbol{B}$, In all neurons recorded in vivo, 5-HT caused a rapid and drastic increase in firing. $\boldsymbol{C}$, The specific HTR2 agonist mimicked the effect of 5-HT.
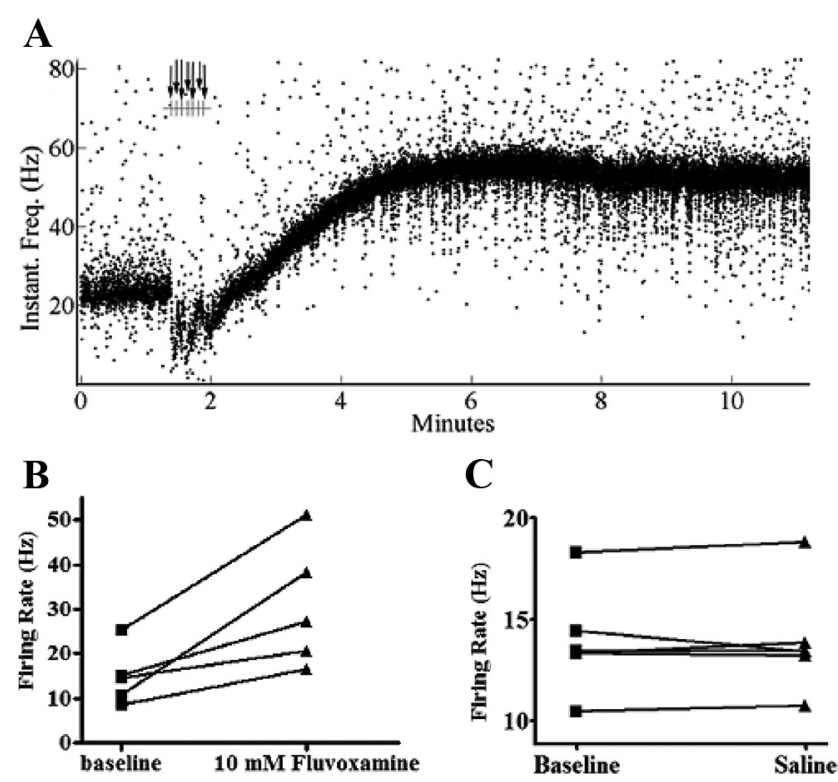

Figure 7. Endogenous 5-HT is sufficient to increase the firing of RA projection neurons in vivo. $\boldsymbol{A}$, Plot of instantaneous firing rate versus time for one example neuron. Fluvoxamine was puffed on at the arrows. There is a fast movement artifact resulting from the force of the puff followed by a slow rise in firing rate. The movement artifact did not occur consistently in other traces. $\boldsymbol{B}$, Group data showing firing rate before and after fluvoxamine application. $\boldsymbol{C}$, Puffing saline onto neurons had no effect on firing rate.

respectively, whereas $H T R 2 B$ had 93,72 , and $75 \%$ identity, and HTR2C had 97, 54, and 55\% identity. Despite the apparent low conservation among full-length avian and mammalian protein coding regions, the four core regions or elements that define a protein fingerprint for all members of the serotonin receptor superfamily (Attwood and Findlay, 1994) showed 92, 86, and $81 \%$ identity at the amino acid level with human HTR2A, HTR2B, and HTR2C, respectively. Moreover, most of the ele- 
Table 1. The effects of blockers of HCN, L-type $\mathrm{Ca}^{2+}$, and T-type $\mathrm{Ca}^{2+}$ channel blockers on firing rates of RA projection neurons

\begin{tabular}{|c|c|c|c|c|c|}
\hline Drug & Channel & Change from baseline & $p$ value & Change in 5-HT-induced increase & $p$ value \\
\hline ZD-7288 & $\mathrm{HCN}$ & $-0.69 \mathrm{~Hz} ; \mathrm{SD}, 0.7346$ & 0.0452 & $-1.723 \mathrm{~Hz}$; SEM, 1.095 & 0.1313 \\
\hline Cesium & $\mathrm{HCN}$ & $-1.17 \mathrm{~Hz} ; \mathrm{SD}, 1.081$ & 0.0738 & $2.988 \mathrm{~Hz} ; \mathrm{SEM}, 1.466$ & 0.0565 \\
\hline Nifedipine & L-type $\mathrm{Ca}^{2+}$ & $-0.153 \mathrm{~Hz} ; \mathrm{SD}, 1.223$ & 0.7718 & $-0.369 \mathrm{~Hz} ;$ SEM, 1.282 & 0.7761 \\
\hline NNC 55-0396 & T-type $\mathrm{Ca}^{2+}$ & $-0.286 \mathrm{~Hz} ; \mathrm{SD}, 1.1193$ & 0.688 & $-1.109 \mathrm{~Hz} ;$ SEM, 0.9117 & 0.2346 \\
\hline
\end{tabular}

ments that identify specific HTR2 receptor subtypes were also recognized by a BLAST-PRINTS search (Wright et al., 1999), including 6/7 elements for HTR2A, 6/8 for HTR2B, and 4/8 for HTR2C. Thus, at the predicted protein level, all three members of the HTR2 gene family appear to encode functional serotonin receptors.

We next identified cDNA clones from the Songbird Neurogenomics Initiative consortium database (ESTIMA: Songbird3) corresponding to zebra finch transcripts of HTR2A (GenBank accession code: CK306989), HTR2B (FE732340), and HTR2C (DV953355). Based on their positions relative to predicted protein coding regions, the clones for HTR2A and HTR2C represent the $3^{\prime}$-untranslated regions, while the clone for HTR $2 B$ includes both some coding and noncoding $3^{\prime}$ regions. To address the sequence specificity of these clones for their respective HTR2s, we aligned each of them with the zebra finch genome using the University of California, Santa Cruz, Zebra Finch Blat Search (http://genome.ucsc.edu/cgi-bin/hgBlat). The results revealed high alignment scores of each clone to their respective single loci, and a lack of significant cross-alignments to other loci, indicating a high degree of sequence specificity for each of these clones.

We next conducted in situ hybridizations using riboprobes. Hybridizations with antisense probes yielded expression patterns that were unique for each probe, qualitatively consistent across animals $(N=6$; Fig. $3 A-C)$, and exclusively cellular (Fig. $\left.3 A^{\prime}, B^{\prime}, C^{\prime}\right)$. The signals were particularly strong for HTR2A and HTR2C. Within the arcopallium, we observed HTR2A-labeled cells almost exclusively contained within nucleus RA (Fig. 3A; RA boundaries indicated by the arrowheads). Similarly, HTR2C labeled many cells in RA but showed a more widespread distribution throughout the arcopallium than HTR2A (Fig. 3C). In contrast, for $H T R 2 B$, we found relatively few and weakly labeled cells within RA, as well as throughout the rest of the brain (Fig. $3 B$ ). Within RA, both HTR2A (Fig. 3A') and HTR2C (Fig. 3 $B^{\prime}$ ) were highly expressed in a discrete population of relatively large neurons. Given their large soma size, it is highly likely that these correspond to projection neurons, as RA projection neurons are $1.5 \times$ larger than RA interneurons with little or no overlap in distributions (Spiro et al., 1999). Hybridizations with sense strand riboprobes did not yield detectable signal (Fig. $3 A^{\prime}, B^{\prime}, C^{\prime}$, inset panels), further supporting probe specificity.

\section{HTR2 receptors mediate the increased firing rate of RA projection neurons}

Bath application to the slices of the selective HTR2 receptor agonist DOI mimicked the increased firing rate following application of 5-HT, with both 1 and $10 \mu \mathrm{M}$ resulting in approximately a doubling of the firing rate (Fig. $4 A ; p=0.001, \Delta \mathrm{FR}=3.8 \mathrm{~Hz}, n=$ 6 , for $1 \mu \mathrm{M}$ DOI). This effect followed a similar timescale to that of 5 -HT but was not reversible in the time periods tested $(\sim 30$ min). DOI occluded the effects of 5-HT: following initial application of $1 \mu \mathrm{M}$ DOI, the addition of 1-10 $\mu \mathrm{M}$ 5-HT (in conjunction with $1 \mu \mathrm{M}$ DOI) resulted in no further increase in firing rate $(p=0.17 ; \Delta \mathrm{FR}=0.17 \mathrm{~Hz} ; n=4)$. Furthermore, the selective HTR2 receptor antagonist ketanserin blocked the 5-HT mediated
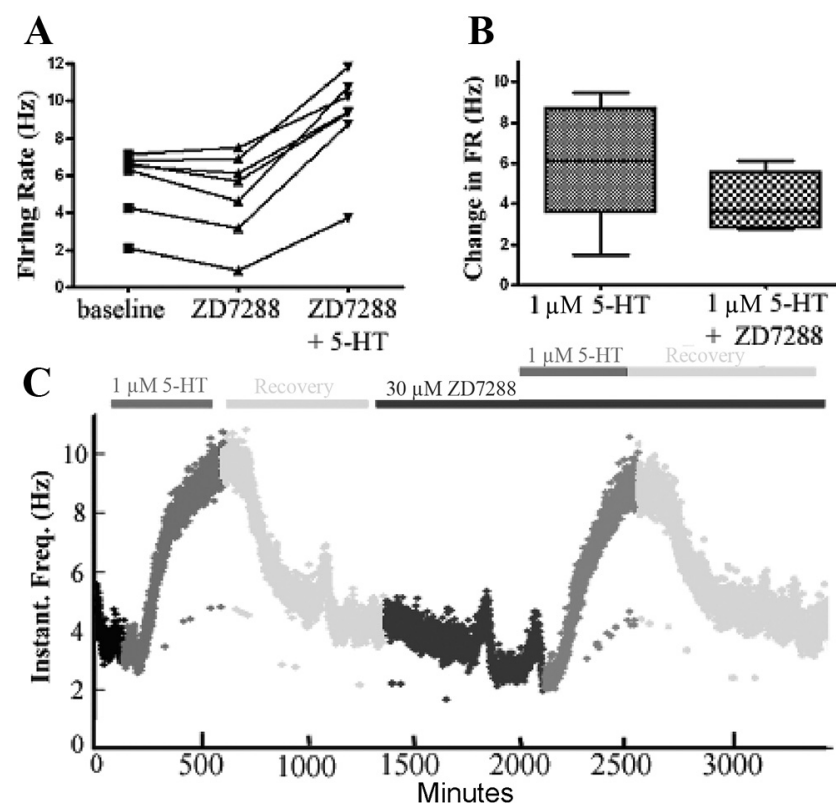

Figure 8. The specific HCN channel blocker ZD-7288 did not inhibit the effects of 5-HT on RA projection neurons. $A$, While ZD-7288 did cause a significant decrease in firing rate ( $p=0.0452$ ) indicating that $\mathrm{HCN}$ channels are present on RA projection neurons, it did not block the effect of 5 -HT. $\boldsymbol{B}$, The change in firing rate elicited by 5 -HT was not significantly different from that in the presence of ZD-7288. C, Plot of firing rate versus time through an example experiment from one neuron.

increase in firing rate, either when applied after 5-HT (Fig. $4 B$; $p=0.3, \Delta \mathrm{FR}=-1.28 \mathrm{~Hz}, n=4)$, or when applied for 3-5 min before 5 -HT (Fig. $4 D$; $p=0.23, \Delta \mathrm{FR}=0.35 \mathrm{~Hz}, n=5$ ). Interestingly, despite the fact that firing rates of RA projection neurons in juveniles during song learning ( $\sim 35-47 \mathrm{~d}$ after hatch) are generally slower than in adults (Adret and Margoliash, 2002), we found that responses to 5-HT and DOI in juveniles were indistinguishable from those in adults (Fig. $5 ; n=10$ and $n=7$ for 5-HT and DOI, respectively). Ketanserin and DOI are quite selective for the HTR2 class of receptors and are also fairly selective for the HTR2A and $2 \mathrm{C}$ receptor types over the $2 \mathrm{~B}$. Because this is the first published report of their use on zebra finch serotonergic receptors, and as the mRNA for all three HTR2 receptor types was found in RA, we are uncomfortable pinpointing this effect of 5-HT to a particular receptor of the HTR2 class at this time.

To verify the observed increase in firing rate in RA is specifically associated with an action of 5-HT, we next applied either dopamine (DA) or the $\mathrm{D}_{1}$ dopaminergic agonist ( \pm )-1-phenyl2,3,4,5-tetrahydro-( $1 H)$-3-benzazepine-7,8-diol hydrobromide [SKF 38393 hydrobromide (SKF)]. Compared with 5-HT, application of $20 \mu \mathrm{M} \mathrm{DA}$ ( $n=4$ cells) to our slice preparation did not influence firing rates of recorded RA neurons, suggesting our observed effects are likely specifically linked to a neuromodulatory action of 5-HT. Interestingly, application of $10 \mu \mathrm{M}$ SKF did cause a slight increase in firing rate $(p<0.01 ; \Delta \mathrm{FR}=1.8 \mathrm{~Hz} ; n=$ 11 ), indicating the presence of $D_{1}$ receptors in RA projection 
A

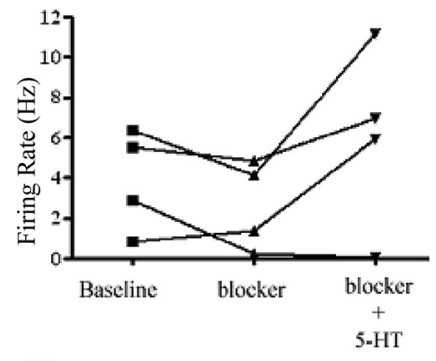

C

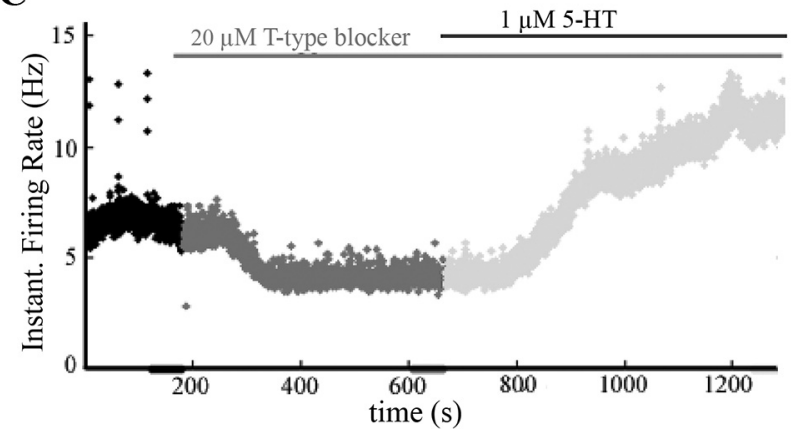

Figure 9. The specific L-type $\mathrm{Ca}^{2+}$ channel blocker nifedipine did not inhibit the effects of 5-HT on RA projection neurons. $\boldsymbol{A}$, Firing rate at baseline (KA plus Ptx), after application of $10-20 \mu \mathrm{m}$ nifedipine, nifedipine plus $1 \mu \mathrm{m} 5-\mathrm{HT}$, and recovery. $\boldsymbol{B}$, The change in firing rate elicited by 5 -HT was not significantly different from that in the presence of nifedipine. $\boldsymbol{C}$, Plot of firing rate versus time through an example experiment from one neuron.

neurons, in agreement with recent reports of mRNA signal there (Kubikova et al., 2010). The change in firing rate, however, was not comparable with that evoked by 5-HT nor did it occlude the effects of 5-HT ( $n=7$ cells) (data not shown), indicating that the observed effect of 5-HT was not due to a nonspecific action of 5-HT on dopaminergic receptors in RA.

\section{In vivo recordings reveal an effect of 5-HT on cell excitability in RA}

Application of between $\sim 25$ and $500 \mathrm{nl}$ of $1 \mathrm{~mm}$ 5-HT (via puffer pipette) in vivo resulted in consistent increases in firing rates of RA projection neurons ( $p<0.0001, \Delta \mathrm{FR}=28.54 \mathrm{~Hz}, n=8$; Fig. $6)$. As in the in vitro preparation, firing rate approximately doubled with 5-HT application, despite the higher baseline spontaneous firing rate of the in vivo preparation $(12.47 \pm 4.18 \mathrm{~Hz})$. The timescale of this effect varied, presumably dependent upon the proximity of the puffer pipette to the neuron being recorded, but was always faster than observed in vitro, often occurring in $<30 \mathrm{~s}$. Consistent with the in vitro data, the specific HTR2 agonist DOI mimicked the effect of 5-HT in vivo $(p=0.01, \Delta \mathrm{FR}=19.2 \mathrm{~Hz}$, $n=5$; Fig. $6 B$ ). Puffing saline onto neurons had no effect on firing rate (Fig. $7 C ; p=0.9, \Delta \mathrm{FR}=-0.03 \mathrm{~Hz}, n=6$ ).

Importantly, when a specific SSRI $(\sim 25-500 \mathrm{nl}$ of $10 \mathrm{~mm}$ fluvoxamine) was applied, we observed a marked increase in firing rate reminiscent of the application of $5-\mathrm{HT}(p=0.02, \Delta \mathrm{FR}=$ 15.9 Hz, $n=5$; Fig. 7). These results indicate that serotonin reuptake transporters are present, as expected, and suggests 5-HT levels may normally be high within RA. The timescale of the rise in firing rate was slower than that following application of 5-HT or DOI, presumably due to the slower process of building up endogenous 5-HT via decreased reuptake (Fig. 7A).

\section{Ionic mechanisms}

Since HTR2s are G-protein-coupled receptors known to have downstream effects on $\mathrm{HCN}$ and $\mathrm{Ca}^{2+}$ channels in other systems
A

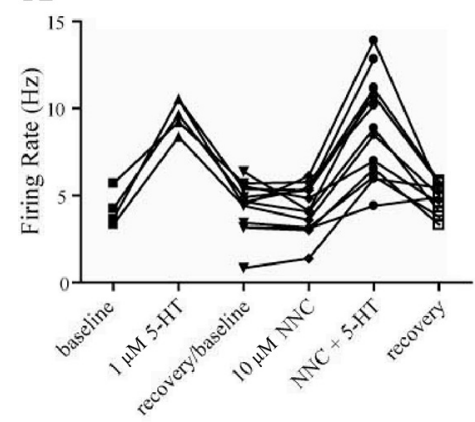

B
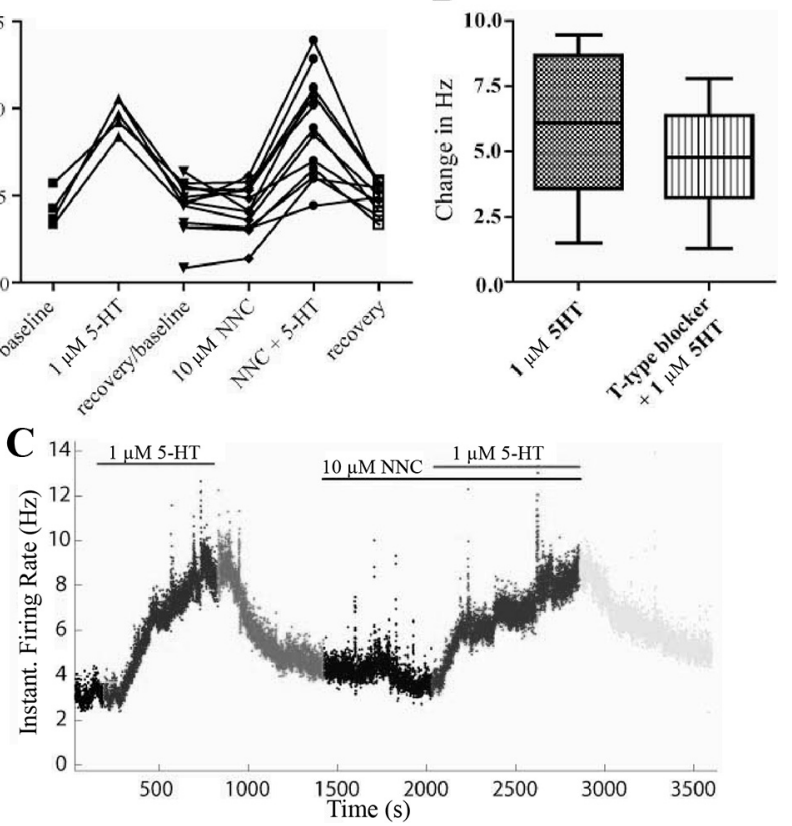

Figure 10. The specific T-type $\mathrm{Ca}^{2+}$ channel blocker NNC 55-0396 did not inhibit the effects of 5-HT on RA projection neurons. $\boldsymbol{A}$, NNC 55-0396 did not cause a significant decrease in baseline firing rate $(p=0.688)$, nor did it block the effect of 5 -HT $(p=0.2346)$. $\boldsymbol{B}$, The change in firing rate elicited by 5 -HT was not significantly different from that in the presence of NNC 55-0396. C, Plot of firing rate versus time through an example experiment from one neuron.

(Gerhardt and van Heerikhuizen, 1997; Liu et al., 2003; Cussac et al., 2008), we next investigated the possibility that either HCN, L-type $\mathrm{Ca}^{2+}$, or T-type $\mathrm{Ca}^{2+}$ channels mediate the observed effect. We used the same extracellular recording technique in acute tissue slices as above, in the presence of KA and Ptx to block fast ionotropic neurotransmitter receptors. We used both the selective HCN channel blocker 4-ethylphenylamino-1,2-dimethyl-6-methylaminopyrimidinium chloride (ZD-7288) and a nonspecific blocker of $\mathrm{HCN}$ channels, $\mathrm{Cs}^{+}$, to determine whether $\mathrm{HCN}$ channels were involved. While both drugs reduced the baseline spontaneous firing rate (Table 1), consistent with the presence of HCN channels in RA projection neurons, neither drug blocked the effects of 5-HT (Fig. 8). Of note, $\mathrm{Cs}^{+}$application during intracellular recordings confirmed the presence of $\mathrm{HCN}$ channels in RA projection neurons (data not shown). Application of specific L-type and T-type $\mathrm{Ca}^{2+}$ channel blockers, nifedipine, and (1S,2S)-2-[2-[[3-(1H-benzimidazol-2-yl) propyl]methylamino] ethyl]-6-fluoro-1,2,3,4-tetrahydro-1-(1methylethyl)-2-naphthalenyl cyclopropanecarboxylate dihydrochloride (NNC 55-0396), respectively, failed to alter baseline firing rate or the effects of 5-HT in RA (Figs. 9, 10, Table 1). These data indicate that $\mathrm{HCN}, \mathrm{L}$-type $\mathrm{Ca}^{2+}$, and T-type $\mathrm{Ca}^{2+}$ channels are unlikely to mediate the effects of HTR2 receptor-driven increases in firing rate.

\section{Discussion}

We describe a novel action of 5-HT: a strong, direct (postsynaptic) excitatory effect on the intrinsic spontaneous neuronal firing rate in song nucleus RA of both adults and juvenile zebra finches. The relatively high 5-HT concentration needed to achieve a halfmaximal effect $(3.85 \mu \mathrm{M})$, along with the fact that this is an excitatory action, predicted that HTR2 receptors mediate this action. The observations that the HTR2 agonist DOI mimics and occludes this effect, and that the HTR2 antagonist ketanserin blocks it, supports this prediction. In situ hybridization confirmed the 
expression of HTR2A, HTR2B, and HTR2C receptor mRNA in large cells in RA, with HTR2B mRNA being expressed at a much lower level than A or C. In an anesthetized in vivo preparation, we found that the effects of focally applied 5-HT (or HTR2 agonist) were qualitatively very similar to those observed in vitro. Importantly, increasing endogenous 5-HT levels by inhibiting the reuptake of natively released 5-HT in RA was sufficient to cause a similar increase in excitability (Fig. 7), indicating that $5-\mathrm{HT}$ is released locally and highly suggestive that its modulatory action in RA is physiologically relevant.

Although birds lack a laminar cortex, song nucleus RA may be considered analogous, if not homologous, to portions of mammalian motor cortex. Specifically, RA projection neurons may be akin to layer V pyramidal output neurons (Karten, 1969, 1991; Reiner et al., 2004). Consistent with this view, HTR2A receptors are also strongly expressed in layer $\mathrm{V}$ pyramidal cells in the mammalian cortex, where they are thought to mediate the effects of many antipsychotic medications and hallucinogenic drugs (Jakab and Goldman-Rakic, 1998; Lambe et al., 2000). In particular, HTR2A receptor activation in layer $\mathrm{V}$ pyramidal neurons of prefrontal cortex leads to a striking increase in EPSCs. Here, we have reported an increase in electrical excitability, mediated through the same receptors, and present in analogous regions. The source of HTR2A-driven increase in EPSCs in mammalian cortex is under some debate (Zhou and Hablitz, 1999; Lambe and Aghajanian, 2001; Marek et al., 2001), although a recent study discovered a subset of neurons that fire spontaneously in response to the addition of 5-HT, which would be consistent with the present study (Béique et al., 2007). The function of these receptors under natural conditions is unknown. 5-HT acts at multiple sites throughout the mammalian CNS and can cause modulation of auditory responses. For example, 5-HT plays a role in modulating auditory responses in the inferior colliculus during different social contexts (Hurley and Hall, 2010). Because the avian song control circuit shows similar sorts of modulation, it is possible that $5-\mathrm{HT}$ also participates in neural modulation at multiple sites.

Given that $100 \%$ of the neurons we recorded in RA responded to 5-HT, endogenous 5-HT is present in RA (Barclay and Harding, 1988) (Fig. 7), and mRNAs encoding HTR2 receptors, particularly HTR2A/2C, are abundant, serotonergic mechanisms appear highly suited for modulating vocal-motor activity within zebra finch nucleus RA. The observed change in spontaneous firing rate is likely intrinsic to RA projection neurons (postsynaptic), as the presence of KA and Ptx do not appear to change the results qualitatively (in vitro vs in vivo experiments). We hypothesize that 5-HT acts here as a permissive signal, perhaps even as a sort of attention-related modulator, exciting neurons (and the entire RA circuitry) to a heightened state. This increase in excitability and spontaneous firing would appear to add noise to the system, not allowing for more precise coding and vocal output but rather might be a mechanism necessary for sensorimotor learning, perhaps allowing neurons to attain a more plastic state. This view suggests a number of testable hypotheses, such as (1) $5-\mathrm{HT}$ is necessary for sensorimotor song learning and (2) 5-HT levels should be higher during song learning.

In adulthood, norepinephrine (NE) decreases and often ceases spontaneous activity in RA projection neurons (Solis and Perkel, 2006), leading to an increase in the signal-to-noise ratio of activity propagated along the DMP. Acetylcholine content in RA increases during the critical period (Sakaguchi and Saito, 1991; Sakaguchi, 1995) and has been reported to be involved in LTP of field potentials within RA (Salgado-Commissariat et al., 2004).
Additionally, the presence of mRNA encoding $D_{1}$ dopamine receptors has recently been demonstrated in RA (Kubikova et al., 2010), a finding that we extend here by showing a functional effect. The fact that 5-HT causes such a marked increase in the firing rate of RA neurons, with opposite sign from the effects of $\mathrm{NE}$, suggests neuromodulators may fine-tune the properties of RA to function optimally under a variety of behavioral situations. This would include the production of undirected versus directed singing, conditions that are known to be associated with the differential activation of catecholaminergic systems. It will be intriguing to investigate whether serotonergic activity is also differentially associated with different singing modes.

The HTR2 class of receptors comprises three distinct receptor subtypes $(\mathrm{A}-\mathrm{C})$, which based on comparative genomic data are highly conserved among humans, rodents, chicken, and zebra finch. The HTR2A and HTR2C receptors are much more similar to each other than to HTR2B, and the specific agonist (DOI) and antagonist (ketanserin) that we used here, although not separating between $2 \mathrm{~A}$ and $2 \mathrm{C}$ subtypes, are generally considered sufficiently selective to rule out an HTR2B receptor action. Consistent with this view, our in situ hybridization data indicate that mRNAs encoding HTR2A and HTR2C are highly expressed within neurons in RA. In contrast, HTR2B mRNA is expressed at low levels and possibly present in relatively few RA neurons. It thus seems unlikely that the HTR2B receptor exerts major actions within RA. Development of more specific ligands and further studies focusing on other neuron and receptor types, as well as synaptic strength and circuit properties, will be critical to a more full understanding of the effects of 5-HT on song production. The basic anatomy of the serotonergic system is conserved across a wide variety of vertebrates, including mammalian and avian lineages. While a projection from the raphe to RA has not been shown directly in the zebra finch, the high homology of this system across vertebrates makes it highly likely the raphe nuclei are the source of 5-HT in RA.

Understanding how 5-HT modulates neural circuits and affects behavior is crucial from a health care perspective, but the complexity of both the serotonergic system and the behaviors it modulates has made progress difficult. We have identified a clear effect of 5-HT in a population of neurons necessary for song production - an increase in excitability of RA projection neurons via HTR2 receptors. Intriguingly, these same receptors are known to modulate associative learning in a number of rodent systems and also to underlie the actions of many hallucinogenic drugs in analogous brain regions. Deciphering how 5-HT modulates song production and learning in the zebra finch will inform our understanding of how 5-HT modulates behavior in humans.

\section{References}

Abarbanel HD, Gibb L, Mindlin GB, Talathi S (2004) Mapping neural architectures onto acoustic features of birdsong. J Neurophysiol 92:96-110.

Adret P, Margoliash D (2002) Metabolic and neural activity in the song system nucleus robustus archistriatalis: effect of age and gender. J Comp Neurol 454:409-423.

Araneda R, Andrade R (1991) 5-Hydroxytryptamine 2 and 5-hydroxytryptamine $1 \mathrm{~A}$ receptors mediate opposing responses on membrane excitability in rat association cortex. Neuroscience 40:399-412.

Attwood TK, Findlay JB (1994) Fingerprinting G-protein-coupled receptors. Protein Eng 7:195-203.

Barclay SR, Harding CF (1988) Androstenedione modulation of monoamine levels and turnover in hypothalamic and vocal control nuclei in the male zebra finch: steroid effects on brain monoamines. Brain Res 459:333-343.

Béïque JC, Imad M, Mladenovic L, Gingrich JA, Andrade R (2007) Mechanism 
of the 5-hydroxytryptamine $2 \mathrm{~A}$ receptor-mediated facilitation of synaptic activity in prefrontal cortex. Proc Natl Acad Sci U S A 104:9870-9875.

Bruford EA, Lush MJ, Wright MW, Sneddon TP, Povey S, Birney E (2008) The HGNC Database in 2008: a resource for the human genome. Nucleic Acids Res 36:D445-D448.

Cussac D, Boutet-Robinet E, Ailhaud MC, Newman-Tancredi A, Martel JC, Danty N, Rauly-Lestienne I (2008) Agonist-directed trafficking of signalling at serotonin 5-HT2A, 5-HT2B, and 5-HT2C-VSV receptors mediated $\mathrm{Gq} / 11$ activation and calcium mobilisation in $\mathrm{CHO}$ cells. Eur J Pharmacol 594:32-38.

Dubovsky SL, Thomas M (1995) Serotonergic mechanisms and current and future psychiatric practice. J Clin Psychiatry 56 [Suppl 2]:38-48.

Fiete IR, Fee MS, Seung HS (2007) Model of birdsong learning based on gradient estimation by dynamic perturbation of neural conductances. J Neurophysiol 98:2038-2057.

Gale SD, Perkel DJ (2010) A basal ganglia pathway drives selective auditory responses in songbird dopaminergic neurons via disinhibition. J Neurosci 30:1027-1037.

Gerhardt CC, van Heerikhuizen H (1997) Functional characteristics of heterologously expressed 5-HT receptors. Eur J Pharmacol 334:1-23.

Gibb L, Gentner TQ, Abarbanel HD (2009) Inhibition and recurrent excitation in a computational model of sparse bursting in song nucleus HVC. J Neurophysiol 102:1748-1762.

Glanzman DL, Mackey SL, Hawkins RD, Dyke AM, Lloyd PE, Kandel ER (1989) Depletion of serotonin in the nervous system of Aplysia reduces the behavioral enhancement of gill withdrawal as well as the heterosynaptic facilitation produced by tail shock. J Neurosci 9:4200-4213.

Harvey JA (2003) Role of the serotonin 5- $\mathrm{HT}_{2 \mathrm{~A}}$ receptor in learning. Learn Mem 10:355-362.

Hurley LM, Hall IC (2010) Context-dependent modulation of auditory processing by serotonin. Hear Res. Advance online publication. Retrieved August 16, 2011. doi:10.1016/j.heares.2010.12.015.

Jakab RL, Goldman-Rakic PS (1998) 5-Hydroxytryptamine 2A serotonin receptors in the primate cerebral cortex: possible site of action of hallucinogenic and antipsychotic drugs in pyramidal cell apical dendrites. Proc Natl Acad Sci U S A 95:735-740.

Karten H (1969) Comparative and evolutionary aspects of the vertebrate central nervous system. Ann N Y Acad Sci 167:164-179.

Karten H (1991) Homology and evolutionary origins of the "neocortex." Brain Behav Evol 38:264-272.

Kubikova L, Wada K, Jarvis ED (2010) Dopamine receptors in a songbird brain. J Comp Neurol 518:741-769.

Lambe EK, Aghajanian GK (2001) The role of Kv1.2-containing potassium channels in serotonin-induced glutamate release from thalamocortical terminals in rat frontal cortex. J Neurosci 21:9955-9963.

Lambe EK, Goldman-Rakic PS, Aghajanian GK (2000) Serotonin induces EPSCs preferentially in layer $\mathrm{V}$ pyramidal neurons of the frontal cortex in the rat. Cereb Cortex 10:974-980.

Leblois A, Wendel BJ, Perkel DJ (2010) Striatal dopamine modulates basal ganglia output and regulates social context-dependent behavioral variability through $D_{1}$ receptors. J Neurosci 30:5730-5743.

Liu Z, Bunney EB, Appel SB, Brodie MS (2003) Serotonin reduces the hyperpolarization-activated current $\left(I_{\mathrm{h}}\right)$ in ventral tegmental area dopamine neurons: involvement of 5-HT2 receptors and protein kinase C. J Neurophysiol 90:3201-3212.

Lovell PV, Mello CV (2011) Brain expression and song regulation of the cholecystokinin gene in the zebra finch (Taeniopygia guttata). J Comp Neurol 519:211-237.

Marek GJ, Wright RA, Gewirtz JC, Schoepp DD (2001) A major role for thalamocortical afferents in serotonergic hallucinogen receptor function in the rat neocortex. Neuroscience 105:379-392.

Meitzen J, Perkel DJ, Brenowitz EA (2007) Seasonal changes in intrinsic electrophysiological activity of song control neurons in wild song sparrows. J Comp Physiol A Neuroethol Sens Neural Behav Physiol 193:677-683.

Monti JM (2010) Serotonin 5- $\mathrm{HT}_{2 \mathrm{~A}}$ receptor antagonists in the treatment of insomnia: present status and future prospects. Drugs Today (Barc) 46:183-193

Mooney R (1992) Synaptic basis for developmental plasticity in a birdsong nucleus. J Neurosci 12:2464-2477.

Mooney R (2009) Neural mechanisms for learned birdsong. Learn Mem 16:655-669.

Nottebohm F (2005) The neural basis of birdsong. PLoS Biol 3:e164.

Olfson M, Marcus SC (2009) National patterns in antidepressant medication treatment. Arch Gen Psychiatry 66:848-856.

Park KH, Meitzen J, Moore IT, Brenowitz EA, Perkel DJ (2005) Seasonallike plasticity of spontaneous firing rate in a songbird pre-motor nucleus. J Neurobiol 64:181-191.

Reiner A, Perkel DJ, Bruce LL, Butler AB, Csillag A, Kuenzel W, Medina L, Paxinos G, Shimizu T, Striedter G, Wild M, Ball GF, Durand S, Güntürkün O, Lee DW, Mello CV, Powers A, White SA, Hough G, Kubikova L, et al. (2004) Revised nomenclature for avian telencephalon and some related brainstem nuclei. J Comp Neurol 473:377-414.

Sakaguchi H (1995) Developmental changes in carbachol-stimulated phosphoinositide turnover in synaptoneurosomes of the robust nucleus of the archistriatum in the zebra finch. Neuroreport 6:1901-1904.

Sakaguchi H, Saito N (1991) Developmental change of cholinergic activity in the forebrain of the zebra finch during song learning. Brain Res Dev Brain Res 62:223-228.

Salgado-Commissariat D, Rosenfield DB, Helekar SA (2004) Nicotinemediated plasticity in robust nucleus of the archistriatum of the adult zebra finch. Brain Res 1018:97-105.

Sizemore M, Perkel DJ (2008) Noradrenergic and $\mathrm{GABA}_{\mathrm{B}}$ receptor activation differentially modulate inputs to the premotor nucleus RA in zebra finches. J Neurophysiol 100:8-18.

Solis MM, Perkel DJ (2005) Rhythmic activity in a forebrain vocal control nucleus in vitro. J Neurosci 25:2811-2822.

Solis MM, Perkel DJ (2006) Noradrenergic modulation of activity in a vocal control nucleus in vitro. J Neurophysiol 95:2265-2276.

Spiro JE, Dalva MB, Mooney R (1999) Long-range inhibition within the zebra finch song nucleus RA can coordinate the firing of multiple projection neurons. J Neurophysiol 81:3007-3020.

Williams GV, Rao SG, Goldman-Rakic PS (2002) The physiological role of $5-\mathrm{HT}_{2 \mathrm{~A}}$ receptors in working memory. J Neurosci 22:2843-2854.

Wright W, Scordis P, Attwood TK (1999) BLAST PRINTS—alternative perspectives on sequence similarity. Bioinformatics 15:523-524.

Zeigler P, Marler P (2004) Behavioral neurobiology of birdsong. Proceedings of a conference. New York, USA, 12-14 December 2002. Ann N Y Acad Sci 1016:xiii-xvii, 1-788.

Zhou FM, Hablitz JJ (1999) Activation of serotonin receptors modulates synaptic transmission in rat cerebral cortex. J Neurophysiol 82:29892999. 